\title{
Prange, Regine, Kunstgeschichte 1750-1900. Eine kommentierte Anthologie
}

\author{
Élisabeth Décultot
}

\section{(2) OpenEdition}

Journals

Édition électronique

URL : http://journals.openedition.org/ifha/1627

DOI : $10.4000 /$ ifha. 1627

ISSN : 2198-8943

\section{Éditeur}

IFRA - Institut franco-allemand (sciences historiques et sociales)

Référence électronique

Élisabeth Décultot, «Prange, Regine, Kunstgeschichte 1750-1900. Eine kommentierte Anthologie », Revue de l'IFHA [En ligne], Date de recension, mis en ligne le 01 janvier 2008, consulté le 22 septembre 2020. URL : http://journals.openedition.org/ifha/1627 ; DOI : https://doi.org/10.4000/ifha.1627

Ce document a été généré automatiquement le 22 septembre 2020

(CIFHA 


\title{
Prange, Regine, Kunstgeschichte 1750-1900. Eine kommentierte Anthologie
}

\author{
Élisabeth Décultot
}

Le présent ouvrage, édité par R.P., rassemble, en version allemande, une série d'extraits de textes-sources sur l'histoire de la théorie et de l'historiographie de l'art entre 1750 et 1900. Il est appelé à constituer l'une des pièces d'une anthologie plus vaste, dont les autres volumes sont encore en préparation. L'objectif affiché par le directeur de la collection, Hubert Locher, est clairement pédagogique : il s'agit de mettre, en traduction allemande, à la disposition d'étudiants d'histoire de l'art des extraits généralement brefs (entre 1 et 8 pages environ) permettant de saisir l'évolution du discours sur l'art et, par là, les grandes étapes de la genèse de l'histoire de l'art conçue comme discipline scientifique. La période prise en compte dans le présent volume, 1750-1900, est cruciale pour l'historiographie de l'art : elle a vu, avec Winckelmann et Caylus, émerger une histoire des styles et des formes artistiques dont on s'accorde généralement à penser qu'elle constitue le premier acte de fondation (ou de refondation, si l'on considère le préalable vasarien) de l'histoire de l'art moderne. De cette évolution épistémologique et institutionnelle, la présente anthologie fournit un aperçu synthétique. Après une introduction de R.P. qui retrace brièvement les aspects majeurs de cette évolution (p. 9-15), l'ouvrage présente les extraits de 32 textes, depuis le Recueil d'antiquités du Comte de Caylus (1752-1767) jusqu'au Holländisches Gruppenporträt d'Alois Riegl (1902), en passant par les œuvres de Winckelmann, Diderot, Luigi Lanzi, Carl Friedrich von Rumohr, Anton Springer, John Ruskin, Gottfried Semper, Herman Grimm, Charles Blanc ou encore Adolf von Hildebrand. Chaque texte, précédé d'une courte introduction, est suivi d'une liste bibliographique recensant les principaux ouvrages de l'auteur ainsi que quelques titres de littérature secondaire. L'ensemble est accompagné d'une bibliographie générale et d'un index des noms propres. Ainsi conçu, l'ouvrage paraît tout à fait propre à donner aux historiens de l'art soucieux de se former à l'histoire de leur propre discipline une vue synthétique des " grands » textes de la tradition. 
Élisabeth Décultot (Centre National de la Recherche Scientifique) 